\title{
Ground-Based Monitoring of the Solar Wind Geoefficiency
}

\author{
Oleg Troshichev \\ Arctic and Antarctic Research Institute \\ Russia
}

\section{Introduction}

The Earth's magnetosphere is a result of the solar wind impact on the dipole-like geomagnetic field. The form and size of geomagnetosphere are basically determined by the solar wind dynamic pressure, whereas unsteady processes within the magnetosphere affecting the human activity under name of magnetic storms and substorms are due to variations of the magnetic field transported by the solar wind plasma. This field, known as interplanetary magnetic field (IMF), is governed by solar activity and can reverse its direction and vary in amplitude a ten times. As soon as the space-borne measurements of solar wind parameters started, it became clear that southward IMF (opposite in direction to the Earth magnetic field) is one of the most geoeffective solar wind characteristics. The perfect relationship was found between southward IMF $\left(B_{Z S}\right)$ and such indicators of magnetic activity as a planetary Kp index (Fairfield \& Cahill, 1966; Wilcox et al., 1967; Rostoker \& Fälthammar, 1967; Baliff et al., 1967), AE index of magnetic activity in the auroral zone (Pudovkin et al., 1970; Arnoldy, 1971; Foster et al., 1971; Kokubun, 1972; Meng et al., 1973), magnetic storm Dst index (Hirshberg \& Colburn, 1969; Kokubun, 1972; Kane, 1974; Russel et al., 1974). Since the correlation of magnetic activity with the solar wind fluctuations distinctly increased when the product of the solar wind speed and southward IMF was taken into account (Rostoker \& Fälthammar, 1967; Garrett et al., 1974; Murayama \& Hakamada, 1975), the conclusion was made that the interplanetary electric field $\boldsymbol{E}=v \times \boldsymbol{B}_{Z S}$ plays a crucial part in the solar wind-magnetosphere coupling (Rostoker \& Fälthammar, 1967).

Various combinations of solar wind parameters (basically, the interplanetary electric field and the solar wind density and speed) were repeatedly examined to establish the best function for description of the solar wind-magnetosphere coupling. The most well-known functions are an parameter $\varepsilon=l_{0}^{2} v B^{2} \sin ^{4}\left(\theta_{d} 2\right)$, firstly presented by Perreault \& Akasofu (1978), electric field $E_{K L}=v B_{T} \sin ^{2}\left(\theta_{d} / 2\right)$ introduced in practice by Kan \& Lee (1979), and rectifying function $E_{Y}=v B_{Z S}$ (Reiff \& Luhmann, 1986), where $v$ is a velocity of the solar wind, $B$ is IMF intensity, $B_{Y}, B_{Z}$ and $B_{Z S}$ are azimuthal, vertical and southward IMF components, $B_{T}$ is transverse IMF component $B_{T}=\left\{\left(B_{Y}\right)^{2}+\left(B_{Z}\right)^{2}\right\}^{1 / 2}$, and $\theta_{c}$ is an angle between $B_{T}$ component and the geomagnetic $Z$-axis. A precise formula for the solar wind-magnetosphere coupling function has not yet been agreed so far, and other functions, in number of more than ten, are also used in practice. 
In attempts to derive an universal solar wind-magnetosphere coupling function, Newell et al. $(2007,2008)$ investigated behavior of 10 variables, characterizing the magnetosphere state, in relation to different coupling functions. The comprehensive investigations did not reveal a unique coupling function applicable for any circumstances and conditions, but it was noted (Newell et al., 2008), that the unique coupling function, if it exists, must involve the solar wind velocity $v$ to the first (or a little higher) power, transverse IMF component $B_{T}$ to the first (or a little lower) power, and sine of IMF clock angle $\theta_{c}$ to the second (or more) power. It is easy to see that coupling function $E_{K L}$ (Kan \& Lee, 1979) is well consistent with these requirements.

Coupling functions are used to characterize the solar wind geoefficiency. As this takes place, the solar wind parameters are measured outside the magnetosphere, at present on board ACE spacecraft positioned in Lagrange point (L1) at a distance of $\sim 1.5$ millions $\mathrm{km}$ from Earth. As a consequence, an actual value of the solar wind parameters at magnetopause can essentially differ from those monitored on board ACE spacecraft, even if they are timeshifted to the magnetosphere. Besides, a very high level of magnetic field turbulence is typical of region between the bow shock and magnetopause with incorporation of nonlinear processes within the boundary magnetosphere (Rossolenko et al., 2009), and it is unlikely to wait that changes in the solar wind parameters are converted in their true shape into the magnetosphere processes, while transmitting a signal through the highly turbulent region. Hence it is very desirable to monitor the solar wind energy that entered into the magnetosphere. It is suggested to use for this purpose a ground-based PC index put forward by Troshichev et al. (1988) as a index of magnetic activity in the polar cap.

\section{Physical backgrounds and method for the PC derivation}

Distribution and intensity of magnetic activity in the Earth's polar caps is determined by orientation and power of the interplanetary magnetic field, particular types of the polar cap magnetic disturbances being related to the IMF southward $B_{Z S}$ (Nishida, 1968), azimuthal BY (Svalgaard, 1968; Mansurov, 1969) and northward B BN (Maezawa, 1976; Kuznetsov \& Troshichev, 1977) components. Distribution of magnetic disturbances on the ground level is commonly described by systems of equivalent currents being hypothetic currents, providing the observed magnetic effect on the ground surface. Figure 1 demonstrates DP2, DP3 and DP4 current systems derived for polar cap disturbances associated with action of southward, northward and azimuthal IMF components, respectively (Kuznetsov \& Troshichev, 1977; Troshichev \& Tsyganenko, 1978). In addition, the DP0 disturbances have been separated (Troshichev \& Tsyganenko, 1978) which are observed irrespective of the IMF, but well correlate with the solar wind velocity $v$ in the second power (Sergeev \& Kuznetsov, 1981) that makes it possible to associate them with the solar wind dynamic pressure. DP2 and DP0 current systems are terminated by the latitudes of $\Phi=50-60^{\circ}$ (Troshichev, 1975) and focuses in these current vortices are located just right where the intense magnetospheric field-aligned currents are regularly observed.

Measurements on board spacecrafts OGO-4 (Zmuda \& Armstrong, 1974) and TRIAD (Iijima \& Potemra, 1976) showed that field-aligned currents (FAC) are distributed in two regions aligned with the auroral oval. Region 1 FAC system consists of a layer of field-aligned currents on the poleward boundary of the auroral oval, with currents flowing into the ionosphere in the morning sector and flowing out of the ionosphere in the evening sector. 

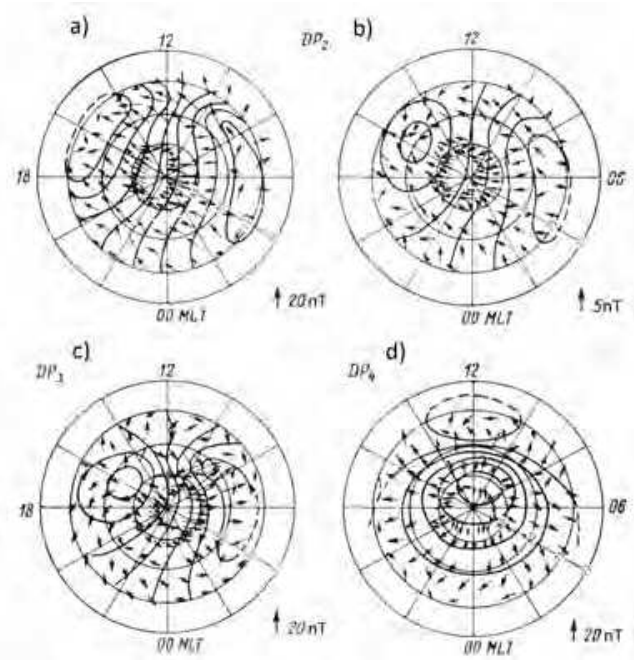

Fig. 1. Current systems of DP2, DP3 and DP4 disturbances generated by variations of IMF components: (a) southward $\mathrm{B}_{\mathrm{ZS}}=-1 \mathrm{nT}$, (b) southward $\mathrm{B}_{\mathrm{ZS}}=-0.25 \mathrm{nT}$, (c) northward $\mathrm{B}_{\mathrm{ZN}}$, (d) azimuthal $\mathrm{B}_{Y}$ (Troshichev and Tsyganenko, 1978).

Region 2 FAC system with the oppositely directed field-aligned currents is positioned on the equatorward boundary of the oval. The currents in Region 1 demonstrate a strong dependency on southward IMF $B_{Z S}$ (Langel, 1975; Mc Diarmid et al., 1977; Iijima \& Potemra, 1982) or the interplanetary electric field $E_{Y}$ (Bythrow \& Potemra, 1983). The Region 1 FAC system is observed permanently, even during very quiet conditions, whereas Region 2 system becomes available when magnetic disturbances in the auroral zone are developed (Iijima \& Potemra, 1978). Regions 1 and 2 FAC systems are mapped into the equatorial plane of magnetosphere in all magnetosphere models (Antonova et al., 2006). Observations of ion fluxes and magnetic fields made on board DMSP F7 satellite (Iijima et al., 1997), plasma sheet temperature, density, and pressure data inferred from DMSP F8, F9, F10, and F11 satellite measurements at the ionospheric altitudes (Wing and Newell, 2000), measurements of plasma pressure gradients on board the THEMIS satellites (Xing et al., 2009) lead to conclusion that the field-aligned current systems are constantly driven by the pressuregradient forces generated within the closed magnetosphere while it's coupling with the varying solar wind. The azimuthal pressure gradients required to support the Region 1 field-aligned currents have been derived in studies (Stepanova et al., 2004, 2006; Antonova et al., 2011)

The field-aligned currents patterns typical of low and high magnetic activity have been applied to calculate the systems of electric fields and currents in the polar ionosphere (Nisbet et al., 1978; Gizler et al., 1979; Troshichev et al., 1979). The calculated equivalent current systems turned out to be identical to the experimental systems derived from magnetic disturbances observed in the polar caps. The conclusion was made (Troshichev, 1982) that magnetic activity in polar caps is related to the field-aligned currents responding to changes in the solar wind, and the DP2 disturbances can be taken as an indicator of the geoeffective solar wind impacting on the magnetosphere. 
Examination of statistical relationships between the DP2 magnetic disturbances and different interplanetary quantities (Troshichev and Andrezen, 1985) gave the best result for coupling function $E_{K L}$ : the disturbance values $\delta F$ at the near-pole stations Thule (Greenland) and Vostok (Antarctica) turned out to be linearly linked with $E_{K L}$ value. It means that $E_{K L}$ value can be estimated if the scaling coefficients between quantities $E_{K L}$ and $\delta F$ is established. Dependence of $\delta \boldsymbol{F}$ value on ionospheric conductivity is easily taken into account under common conditions, when the polar cap ionosphere is regulated by the solar UV irradiation. These are the physical backgrounds determining a method for the PC index derivation (Troshichev et al., 1988, 2006).

The statistically justified regression coefficients $a$ and $\beta$, which determine the relationship between the coupling function $E_{K L}$ and vector of DP2 magnetic disturbance $\delta F$ at stations Thule and Vostok, are derived at first:

$$
\delta \mathrm{F}=\mathrm{a} \mathrm{E}_{\mathrm{KL}}+\beta
$$

These coefficients are calculated for any UT moment of each day of the year since orientation of DP2 disturbances at stations is dependent on local time and slightly changed from summer to winter. To determine the statistically justified orientation of the DP2 disturbances vector (i.e. angle $\phi$ between the disturbance vector and the dawn-dusk meridian), the correlation between $\delta F$ and $E_{K L}$ is calculated for all angles $\phi$ in the range of $\pm 90^{\circ}$ from the dawn-dusk orientation on the basis of large set of data (some years). The angle $\phi$ ensuring the best correlation between values $\delta F$ and $E_{K L}$ is fixed and the appropriate regression coefficients $a$ and $\beta$ are calculated. Just these parameters $\phi, a$ and $\beta$ are used in further calculations.

The values $E_{K L}$ were calculated from measurements of solar wind parameters in space, shifted to the sub-solar point (12 RE) using the actual solar wind velocity. Then a time delay $\Delta \mathrm{T} \sim 20 \mathrm{~min}$ is required for an $E_{K L}$ signal to be transferred from the bow shock position to the polar cap. To take into account the effect of ionospheric conductivity variations and its changes in response to solar activity, the $\delta \boldsymbol{F}$ values were estimated in reference to quiet daily curve (QDC) with allowance for QDC change from day to day (Janzhura \& Troshichev, 2008). Usage of a proper QDC, as a level of reference for $\delta \boldsymbol{F}$ values, ensures invariance of the parameters $\alpha, \beta$ and $\phi$ determining relationship between $\delta \boldsymbol{F}$ and $E_{K L}$ irrespective of solar activity (Troshichev et al., 2011a). As an evidence, Figure 2 shows distribution of $\alpha, \beta$ and $\phi$ parameter derived for the Vostok station for epochs of solar maximum (Troshichev et al. 2006) and solar minimum (Troshichev et al., 2011a), and for entire cycle of solar activity (Troshichev et al., 2007, Troshichev \& Janzhura, 2009). One can see that patterns for $\phi$, a and $\beta$ parameters derived independently for different epochs are totally consistent (if make allowance for some difference in their scales). It means that once derived parameters of $\alpha, \beta$ and $\phi$ can be regarded as valid for ever provided the appropriate QDCs are used (additional substantiations can be found in (Troshichev et al., 2011a)).

The parameters $a, \beta$ and $\phi$ established for each UT moment of each day of the year are further used for calculation of PC index of any given time

$$
P C=\xi(\delta F-\beta) / a
$$



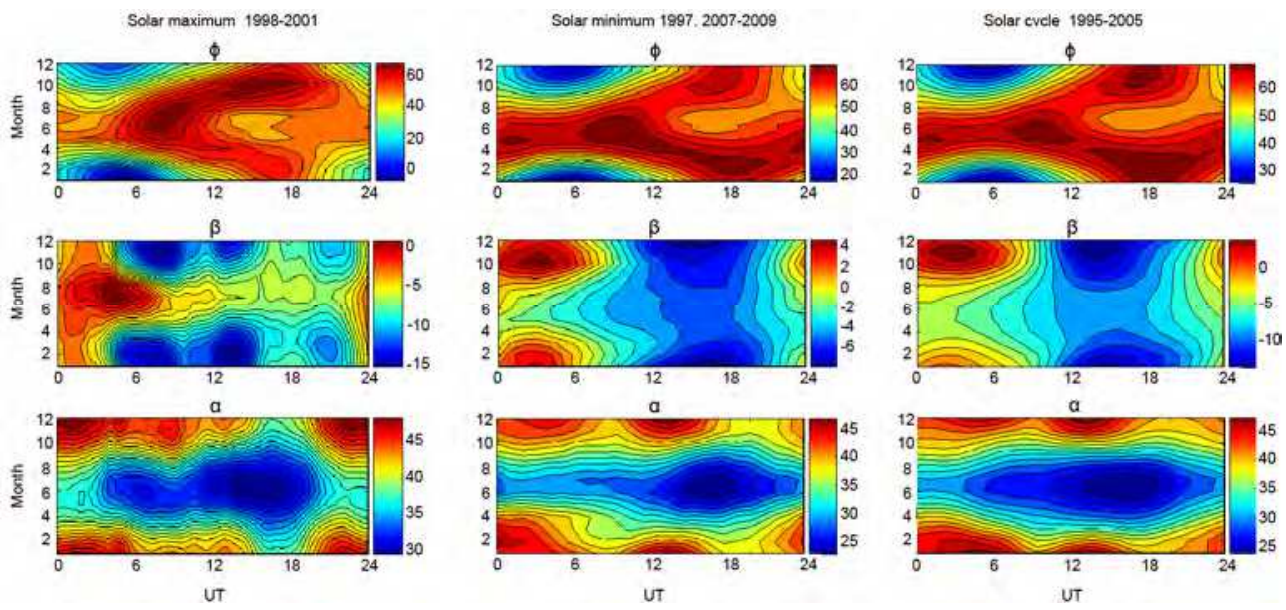

Fig. 2. Parameters $\phi, \beta$ and $a$ for the Vostok station, derived independently for epochs of solar maximum (1998-2001), solar minimum (1997, 2007-2008), and the full cycle of solar activity (1995-2005); the axis of abscises being for UT and axis of ordinates being for a month.

The normalization coefficients $\alpha$ and $\beta$ derived independently for the Thule and Vostok stations eliminate the diurnal and seasonal changes in response of the PC index to changes in $E_{K L}$ field in the summer and winter polar caps. Dimensionality of the scale coefficient $\xi$ is taken equal to 1 for convenience of comparison of PC and $E_{K L}$ values. As an example, Figure 3 shows the run of the calculated PCN (blue) and PCS (red) indices in the northern and southern hemispheres in 1998-2001. One can see a remarkable agreement in behavior of the positive PCS and PCN indices (which are related to DP2 disturbances) irrespective of the season, the largest value of $P C$ about $+20 \mathrm{mV} / \mathrm{m}$ being reached synchronously at both stations. Asymmetry is seen for negative $P C$ index which describes the effect of DP3

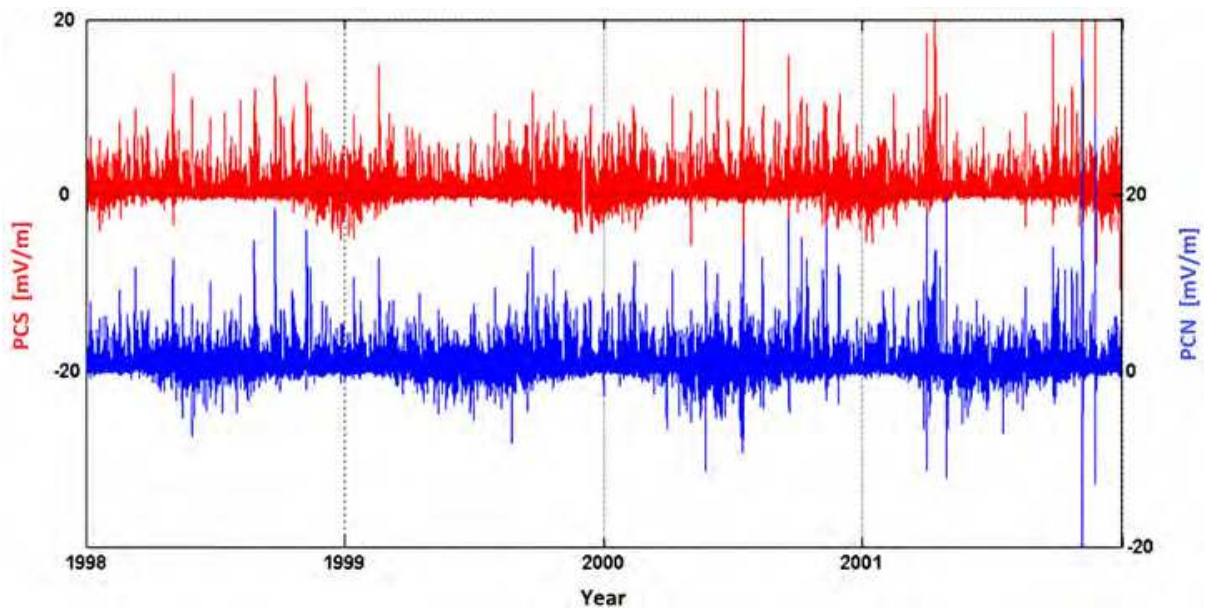

Fig. 3. Run of PCN and PCS indices in 1998-2001 (Troshichev et al., 2006). 
magnetic disturbances responding to the northward IMF influence typical of only the summer polar cap.

\section{PC index response to changes in solar wind dynamic pressure and $E_{K L}$}

Statistically justified relationships between $P C$ index and changes in the interplanetary electric field $E_{K L}$ and solar wind dynamic pressure $P_{S W}$ were examined in (Troshichev et al., 2007) on the example of the interplanetary shocks, which are commonly accompanied by the clearly defined and significant solar wind dynamic pressure pulses and strong oscillations of the interplanetary magnetic field. To estimate the value $E_{K L}$ and the solar wind dynamic pressure $P_{S W}$ the 5-min averaged data from the ACE satellite for 1998-2002 were used. These parameters were reduced to the magnetopause, the time of the signal passage from the ACE location to the magnetosphere been taken into account with allowance for the real solar wind speed for each particular event. Allowance for additional delay time $\tau_{D} \sim 20$ minutes typical of the signal passage from the magnetopause to the polar cap and its transformation into magnetic activity was not made in this case.

Only interplanetary shocks with sudden pressure pulses $\Delta P_{S W}>4 \mathrm{nPa}$ starting against the background of the steady quiet pressure level lasting no less than 6 hours were examined in the analysis $(\mathrm{N}=62)$. The moment of maximum derivative $\mathrm{dP} / \mathrm{dt}$ was identified as a pressure pulse onset. Just this moment is taken as a key ("zero") date for the epoch superposition method, other characteristics - $E_{K L}, P C$, and real $P_{S W}$ - being related to the key date. $P C$ indices were classified as summer and winter ones (PCsummer and PCwinter), instead of $P C N$ and PCS indices. To separate the overlapping effects of the electric field and dynamic pressure, the behavior of averaged characteristics $P_{S W}, E_{K L}$ and $P C$ was examined under different restrictions imposed in turn on (1) the coupling function $E_{K L},(2)$ the magnitude of the pressure $P_{S W}$ after the jump, and (3) the rate of the pressure increase $\left(d P_{S W} / d t\right)$, the other two quantities being successively kept invariant at the same time.

Analysis of the relationships between the averaged $E_{K L}$ and $P C$ quantities under conditions of varying restrictions imposed on the $E_{K L}$ value $\left(1>E_{K L}>0 \mathrm{mV} / \mathrm{m}, 3>E_{K L}>1 \mathrm{mV} / \mathrm{m}, E_{K L}\right.$ $>3 \mathrm{mV} / \mathrm{m}$ ) with the practically arbitrary values of the pressure jump (pressure gradient $\Delta P_{S W}>2 \mathrm{nPa}$ and derivative $d P / d t>0.04 \mathrm{nPa} / \mathrm{min}$ ) showed that the $P C$ index starts to growth within few minutes after the pressure jump, almost simultaneously with the $E_{K L}$ increase. Nevertheless, the maximal magnetic activity in the polar caps is reached about 15 30 minutes after the $E_{K L}$ maximums, the corresponding average $E_{K L}$ and PC values being almost identical. Relationships between averaged $P_{S W}, E_{K L}$ and $P C$ under varying restrictions imposed on the pressure magnitude suggest that the dynamic pressure gradient, not the pressure level, affects the $P C$ index. Indeed, the $P C$ index rose just after the pressure jump and descended about 1 hour later irrespective of the persistent high level of the dynamic pressure.

Figure 4 demonstrates relationship between the averaged $P_{S W}, E_{K L}$ and $P C$ values under varying restrictions imposed on the pressure growth rate $(d P / d t)$ : (a) $0.2>(d P / d t)>0.1$ $\mathrm{nPa} / \mathrm{min}$, (b) $0.3>(d P / d t)>0.2 \mathrm{nPa} / \mathrm{min}$ and (c) $(d P / d t)>0.3 \mathrm{nPa} / \mathrm{min}$, the values of $E_{S W}$ and $\Delta P_{S W}$ being arbitrary. One can see that the electric field $E_{K L}$ increases when the dynamic pressure growth rate arises: the sharper is front of the pressure enhancement, the larger are the changes of $E_{K L}$ on the front. Average $P C$ indices and $E_{K L}$ start to increase some minutes 

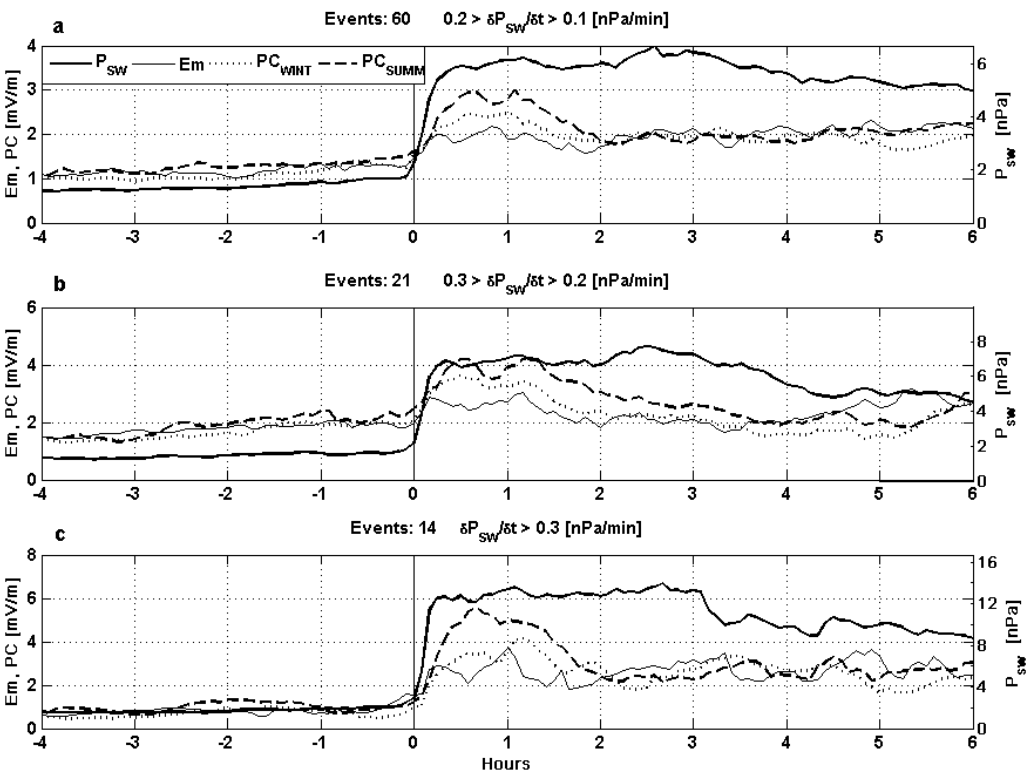

Fig. 4. Relationship between averaged $P_{S W}, E_{K L}$ and $P C$ quantities under varying restrictions imposed on of the pressure growth rate $(d P / d t)$ : (a) $0.2>(d P / d t)>0.1 \mathrm{nPa} / \mathrm{min}$, (b) $0.3>$ $(d P / d t)>0.2 \mathrm{nPa} / \mathrm{min}$ and $(\mathrm{c})(d P / d t)>0.3 \mathrm{nPa} / \mathrm{min}$, the values of $E_{K L}$ and $\Delta P_{S W}$ being arbitrary (Troshichev et al., 2007) $E_{K L}$ quantity is denoted here as Em.

after the pressure jump, and the $P C$ indices maximums follow the electric field maximums with a common delay time of $\sim 15-30$ minutes. The $P C$ index remains increased only 1-1.5 hours after a sharp pressure increase, and then the polar cap magnetic activity quickly decays in agreement with $E_{K L}$ behavior.

The excess of the $P C$ index over the appropriate $E_{K L}$ value is typical of the pressure jump conditions: $P C$ Sum $\sim 3 \mathrm{mV} / \mathrm{m}$ for $E_{K L} \sim 2 \mathrm{mV} / \mathrm{m}$ and $0.2>(d P / d t)>0.1 \mathrm{nPa} / \mathrm{min}$ (Fig. $4 \mathrm{a}$ ); PCsum $\sim 4.2 \mathrm{mV} / \mathrm{m}$ for $E_{K L} \sim 2.5-2.8 \mathrm{mV} / \mathrm{m}$ and $0.3>(d P / d t)>0.2 \mathrm{nPa} / \mathrm{min}$ (Fig. $\left.4 \mathrm{~b}\right)$; PCsum $\sim 5.6 \mathrm{mV} / \mathrm{m}$ for $E_{K L} \sim 2.5-3 \mathrm{mV} / \mathrm{m}$ and $(d P / d t)>0.3 \mathrm{nPa} / \mathrm{min}$ (Fig. $4 \mathrm{c}$ ). The discrepancies between the values of $E_{K L}$ and $P C$ indices turn out to be proportional to the corresponding values of $\Delta P_{S W}$ and can be assigned just to the influence in the solar wind dynamic pressure. It makes it possible to conclude that an effect of pressure gradient $\sim 1 \mathrm{nPa}$ is approximately equivalent to effect of $E_{K L} \approx 0.33 \mathrm{mV} / \mathrm{m}$.

A decisive argument in favor of the pressure gradients influence on polar cap activity could be provided with events when the pressure jumps are not accompanied by electric field changes. Unfortunately, it is not feasible to find sharp pressure increases, which are inconsistent with no any variations of the interplanetary electric field. However, there is a number of pressure decreases divorced from the electric field. Results of the epoch superposition for 94 events with negative pressure gradients $\left(-0.1>d P_{S W} / d t \mathrm{nPa} / \mathrm{min}\right)$ are presented in Figure 5a, where the moment of pressure sudden decrease is taken as a "zero moment". One can see that both summer and winter PC indices started to decrease right after "zero moment" although the mean electric field remained at level of $\sim 2.5 \mathrm{mV} / \mathrm{m}$ 

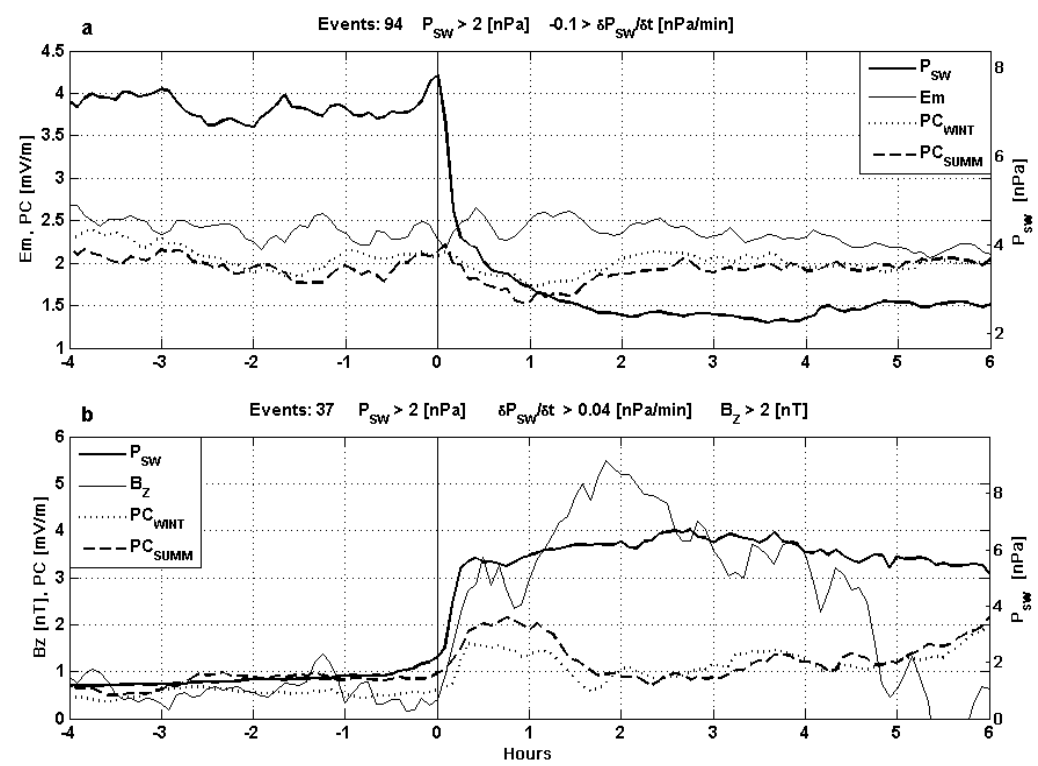

Fig. 5. Relationship between averaged $P_{S W}, E_{K L}$ and $P C$ quantities under conditions of (a) negative pressure gradient $\left(-0.1>d P_{S W} / d t \mathrm{nPa} / \mathrm{min}\right)$, and (b) northward IMF (Troshichev et al., 2007) $E_{K L}$ quantity is denoted here as Em.

before and after the key date. The average decay of the polar cap magnetic activity lasted about 1.5 hours, and the effect was maximal $(\sim 0.5 \mathrm{mV} / \mathrm{m})$ in the summer polar cap. A pure effect of the pressure negative jump in these events is estimated as $1 \mathrm{nPa} \approx 0.25 \mathrm{mV} / \mathrm{m}$. The fact that the $P C$ index decreases in response to negative pressure gradients suggests that the pressure effect in the PC index is reversible and acts under conditions of the pressure rise and fall.

Figure $5 \mathbf{b}$ shows relationship between averaged $P_{S W}$ and $E_{K L}$ under conditions of northward IMF. Since the coupling function $E_{K L}$ reduces to zero when the IMF is northward $\left(B_{Z}>0\right)$, the run of the IMF $B_{Z}$ component is shown in Figure. One can see that the mean $P C$ index increases in response to positive pressure pulses, the ratio $1 \mathrm{nPa} \approx 0.4 \mathrm{mV} / \mathrm{m}$ is valid in this case. Thus, the solar wind pressure growth rate (i.e. jump power $\Delta P_{S W} / \Delta t$ ) proves, after $E_{K L}$, to be the second most important factor for the $P C$ index increase: influence of the dynamic pressure gradient $\Delta P_{S W}=1 \mathrm{nPa}$ on the polar cap magnetic activity is roughly equivalent to effect of the coupling function $\Delta E_{K L}=0.33 \mathrm{mV} / \mathrm{m}$.

The $P C$ index rises in response to the positive dynamic pressure pulses irrespective of IMF polarity (southward or northward). It means that mechanism of the pressure gradients influence on polar magnetic activity is not related to IMF whose effects in polar ionosphere are strongly controlled by the IMF orientation. The $P C$ indices in the summer and winter polar caps demonstrate similar response to solar wind dynamic pressure pulses, but the summer $P C$ value is persistently higher than the winter $P C$ value (up to factor 1.5). The predominant growth of the summer $P C$ index is indicative of important role of ionospheric conductance in mechanism of the pressure pulses effect that implies 
the better conditions for field-aligned currents closure through the well-conducting sunlit ionosphere.

\section{Relation of the PC index to magnetospheric substorms}

Dynamics of magnetic disturbances in the auroral zone is described by the "auroral indices" $A U$ and $A L$ that characterize intensity of magnetic disturbances produced, respectively, by eastward and westward electric currents (electrojets) flowing in the morning and evening sectors of auroral zone. Their total, $A E$ index, is regarded as a measure of disturbance in the auroral zone. During substorm periods a powerful westward electrojet is developed in the midnight auroral zone as a result of substorm current wedge formation (Birkeland, 1908) in response to strongly enhanced auroral particle precipitation and short-circuiting of neutral sheet currents through the high conductivity auroral ionosphere. That is why a sudden increase of the $A L$ index is identified with the magnetospheric substorm onset, the intensity of substorm being evaluated by the $A E$ or $A L$ indices. The substorm sudden onset is usually preceded by gradual increase of westward and eastward electrojets regarded as a substorm growth phase. Growth phase is related to Region 1 FAC enhancement, which is accompanied by progressive intensification of auroral particle precipitation and formation Region 2 FAC system.

Relationship between the $P C$ index and development of the isolated substorms, occurring against the background of magnetic quiescence, was analyzed by Janzhura et al. (2007). The following four classes of isolated magnetic disturbances were examined: weak magnetic bays, short magnetic substorms with duration under 3 hours, long substorms lasting more than 3 hours, and extended substorms, which demonstrate, after sudden onset a slow intensity increase, with maximum being retarded for some hours after the sudden onset.

Relationship between the $P C$ index and progress of the strongest "sawtooth" substorms, whose intensity periodically increases and decreases, was analyzed by Troshichev \& Janzhura (2009). The sawtooth events, developing under influence of a high-speed solar wind with strong fluctuating or a steady southward IMF, are distinguished from usual substorms by a larger local time extent (Lui et al., 2004; Henderson et al., 2006a,b; Clauer et al., 2006). Results (Troshichev et al., 2011b) indicate that a permanently high level of auroral activity is a typical feature of powerful sawtooth substorms. Aurora activity starts long before a magnetic disturbance onset and keeps a high level irrespective of magnetic disturbances. As a result, the close agreement between magnetic disturbance sudden onsets and behavior of aurora and particle injections on the synchronous orbit breaks down in contrast to "classical" substorms which are strongly associated with auroral particle precipitation.

The epoch superposition method, with the time of a substorm sudden onset taken as a key date, was used to reveal regularity in relationship between $P C$ and $A E$ indices in course of different types of substorm. In case of sawtooth substorms observed in 1998-2001 under conditions of the fluctuating southward IMF $(\mathrm{N}=43)$, the relationships between the IMF $\mathrm{Bz}$ and $B y$ components, electric field $E_{K L}$, and $P C$ and $A L$ indices are also examined. Figure 6 integrates results obtained in analyses of Janzhura et al. (2007) and Troshichev \& Janzhura (2009) for magnetic bays (average $A L<200 \mathrm{nT})$, short $(A L>200 \mathrm{nT})$, extended $(A L>200 \mathrm{nT})$ and sawtooth $(A L>500 \mathrm{nT})$ substorms (notice that the scale at the bottom panel is about 


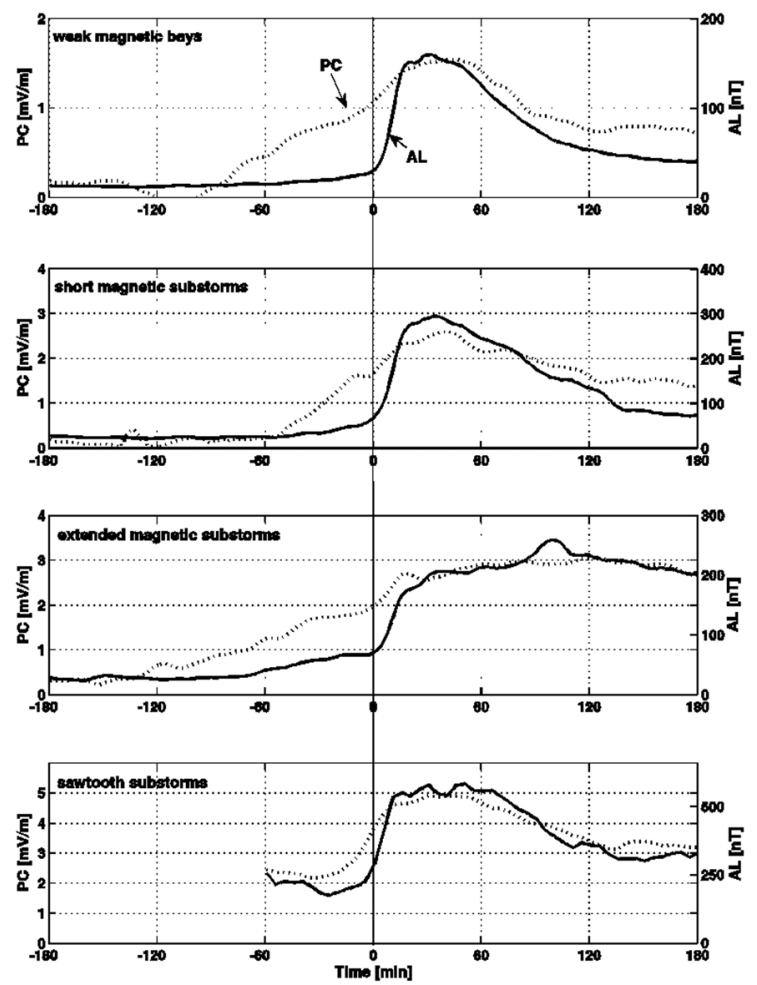

Fig. 6. Relationship between average $P C$ and $A L$ indices for weak magnetic bays (first panel), isolated short and extended substorms (second and third panels), and for sawtooth substorms (forth panel) (Troshichev and Janzhura, 2009).

twice as large as the scale for isolated substorms). One can see that the substorm sudden onset is preceded by the persistent PC index increase irrespective of substorm intensity. Following the generally accepted terminology, we shall name a time interval between a $P C$ growth beginning and an explosive escalation of a magnetic disturbance in the auroral zone as a substorm growth phase. The mean duration of the growth phase is about 1 hour for isolated substorms and about 20-30 minutes for sawtooth substorms. As shown in (Troshichev and Janzhura, 2009) the $P C$ growth phase is determined by the related $E_{K L}$ function growth. In case of sawtooth substorms both $E_{K L}$ and $P C$ quantities stay at a high level after the substorm onset as well. As for magnetic disturbances in the auroral zone, the mean $A L$ index keeps at low level before substorm and starts to grow only $\sim 10$ minutes ahead of the $A L$ sudden onset.

These regularities clearly demonstrate that $P C$ index variations in course of substorm are controlled by interplanetary electric field $E_{K L}$ and that magnetic disturbances in the auroral zone follow the $E_{K L}$ and $P C$ increase. There is a definite $P C$ level required for the substorm onset: in case of isolated substorms the threshold is about $1-2 \mathrm{mV} / \mathrm{m}$, in case of sawtooth substorms the threshold is above $2 \mathrm{mV} / \mathrm{m}$ for. The fall of the $P C$ value below $1 \mathrm{mV} / \mathrm{m}$ is unconditionally followed by the substorm decay. 
Sawtooth disturbances last about 1.5-2 hours like isolated magnetic bays and short substorms, but they principally differ by $P C$ behavior after the expansion phase. In case of isolated substorms, the $P C$ index returns to a quiet level $(<2 \mathrm{mV} / \mathrm{m})$; in case of periodically repetitive substorms $P C$ remains on a high level $(>3 \mathrm{mV} / \mathrm{m})$. If we consider the $P C$ index as a signature of the solar wind energy input into the magnetosphere, an evident conclusion follows that isolated magnetic bays and short substorms are caused by a one-step energy income into the magnetosphere lasting for a short time, whereas isolated long and extended substorms take place if the solar energy is delivered with a different capability for a longer time. Sawtooth substorms are generated when a very powerful energy supply proceeds during a long period.

Thus, the analyses (Janzhura et al., 2007 and Troshichev \& Janzhura, 2009) revealed that the $P C$ index growth is a precursor of substorms development irrespective of a substorm type (isolated or sawtooth) and intensity. The growth phase duration is determined by the $P C$ growth rate: the higher is the rate, the shorter is the growth phase duration. As Figure 7 shows, the $P C$ growth rate is a controlling factor for such important characteristics of magnetic disturbance as an $A L$ growth rate before the substorm sudden onset $\left(A L_{G R}=-0.5+\right.$ $\left.55^{*} P C_{G R}, \mathrm{R}=0.996\right)$ and for maximal intensity of magnetic substorm (ALmax $=114+$ $\left.6570 * P C_{G R}, \mathrm{R}=0.997\right)$. According to last relationship, the ALmax value will reach $\sim 1600 \mathrm{nT}$ when $P C_{G R}$ is $\sim 0.2 \mathrm{mV} / \mathrm{m} / \mathrm{min}$, which is equivalent to the $P C$ jump by $2 \mathrm{mV} / \mathrm{m}$ per 10 minutes, that is observed in the case. Therefore, the average substorm intensity (i.e. magnitude of magnetic disturbance in the auroral zone) is predetermined by the $P C$ growth rate during the growth phase.

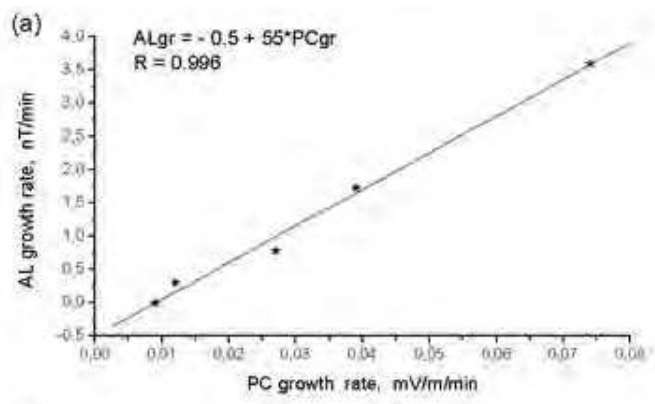

(b)

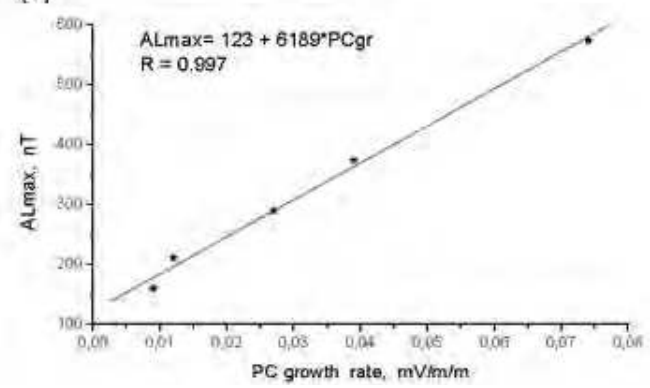

Fig. 7. Dependence of $A L$ growth rate (a) and magnetic substorm intensity ALmax (b) on $P C$ growth rate preceding a sudden onset (Troshichev and Janzhura, 2009). 
The above presented results suggest that the $P C$ index is a signature of solar wind energy that entered into the magnetosphere in course of solar wind-magnetosphere coupling. Indeed, the magnetospheric substorms are always preceded by the $P C$ index growth and start as soon as the $P C$ index exceeds a definite threshold value. Threshold value appears to be a level when the excess of energy incoming into the magnetosphere is over the ordinary energy dissipating in the magnetosphere; if threshold is not reached, the substorm can not begin, irrespective of how long the solar wind energy was income into the magnetosphere. From this point of view, the substorm growth phase is a period of the enhanced rate of energy pumping into the magnetosphere, not a period of energy storage in the magnetosphere. The large $P C$ growth rate indicates that rate of energy pumping into the magnetosphere increases respectively. The greater the energy input, the faster is reached the threshold level; the shorter is the growth phase duration. The higher the energy input rate (i.e. energy input related to the growth phase duration), the larger is excess of incoming energy over the level of ordinary energy dissipation, and the more powerful is substorm. The succeeding substorm development is determined by dynamics of the subsequent input of energy, which is displayed by the $P C$ index run. Thus, the solar wind geoefficiency in case of magnetospheric substorms can be monitored with confidence by the $P C$ index.

\section{Relation of the PC index to magnetic storms}

Magnetic storms are the result of a joint action of magnetopause currents $(D C F)$, which are proportional to the square root of the solar wind dynamic pressure and ring currents $(D R)$ flowing in the inner magnetosphere (Chapman, 1963). The $D R$ current ground effect typically far exceeds the DCF current effect, that is why the magnetic storm intensity is evaluated by the Dst index depicting a longitudinally averaged magnetic field depression at low latitudes (Sugiura, 1976). It is well known (Kamide, 1974; Russel et al., 1974; Burton et al., 1975; Akasofu, 1981) that magnetic storms intensity is dominantly controlled by southward IMF component $\left(B_{Z S}\right)$, whereas the solar wind velocity $(v)$ and density $(n)$ are of minor importance. While investigating solar wind-magnetosphere coupling functions, the best result was obtained for functions including the geoeffective interplanetary electric field $E_{K L}$ (Newell et al., 2008; Spencer et al., 2009).

Relationship between the 1-min PC index behavior and the storm depression development (Dst index) for epoch of solar maximum (1998-2004) has been examined by Troshichev et al. (2011c). Two criteria were used as a basic guideline to choose magnetic storms for the analysis: (1) magnetic storm duration should be longer than 12 hours, (2) magnetic storm depression should be larger than Dst $=-30 \mathrm{nT}$. On the basis of these criteria, 54 magnetic storms were separated for the period of 1998-2004 with a maximal storm intensity varying in the range from $D s t=-30 \mathrm{nT}$ to $D s t=-373 \mathrm{nT}$. For convenience of comparison of the $P C\left(E_{K L}\right)$ behavior with storm development, the main phase of each magnetic depression was divided into two parts: a "growth phase" when magnetic depression increases, and a "damping phase" when magnetic depression decreases, a "recovery phase" being used as before: as a period of a magnetic field slow restoration to the previous undisturbed level.

Since the Dst value is determined by a joint action of two, $D C F$ and $D R$, current sources, the Dst index initial decline can be caused by a $D R$ current growth as well as by a solar wind pressure reduction. In addition, during the solar maximum epoch (1998-2004), magnetic storms were usually following one after other, when a new magnetic storm started against 
the background of the recovery phase of the previous storm. Under these conditions, it would be well to look for another characteristic of storm depression beginnings, independent on the peculiarities of individual magnetic storm development. Referring to results (Janzhura et al., 2007; Troshichev \& Janzhura, 2009) and suggesting that a comparable input of the solar wind energy is required for development of magnetospheric substorms and magnetic storms, the value $P C=2 \mathrm{mV} / \mathrm{m}$ was considered as a possible threshold level.

Examination of 54 chosen storms showed that all of them occurred under condition $P C>2$ $\mathrm{mV} / \mathrm{m}$. To demonstrate that a threshold level $P C=2 \mathrm{mV} / \mathrm{m}$ is a typical feature of relationships between $P C$ (or $E_{K L}$ ) changes and magnetic storm development, the magnetic storms were separated into six gradations according to their intensity, and the averaged $P C\left(E_{K L}\right)$ and Dst quantities for these gradations were examined. The gradations determined by a minimal $D s t$ value are the following: (a) $-30>D$ st $>-50 \mathrm{nT}$, (b) $-50>D$ st $>-80 \mathrm{nT}$, (c) $-80>$ Dst>-100nT, (d) $-100>$ Dst>-120nT, (e) $-130>$ Dst>-160nT, and (f) $-160>D s t>-240 n T$. The method of superposed epochs was used. Correspondingly, the time when the $P C$ index

(a) Dst $=-(30-50) n T, N=8$

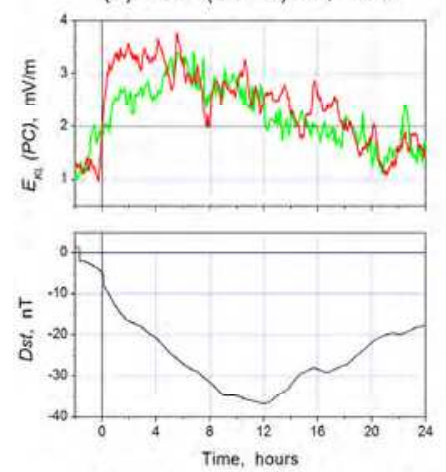

(d) Dst $=-(100-120) n T, N=8$
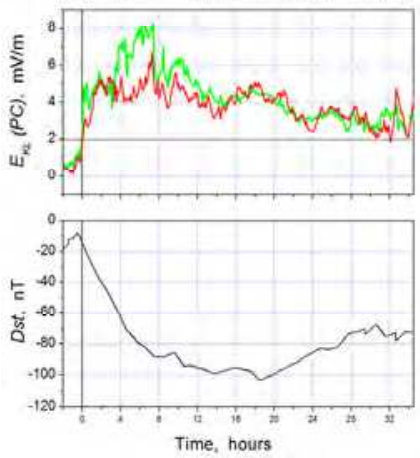

(b) Dst $=-(50-80) n T, N=13$
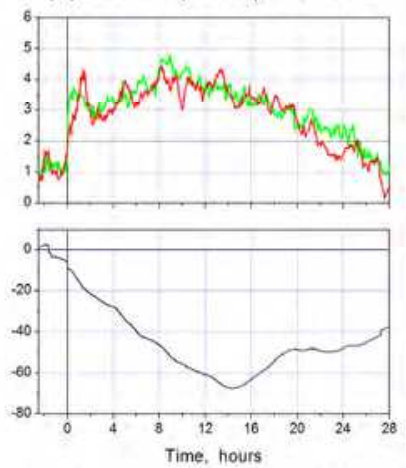

(e) Dst $=-(130-160) n T, N=10$
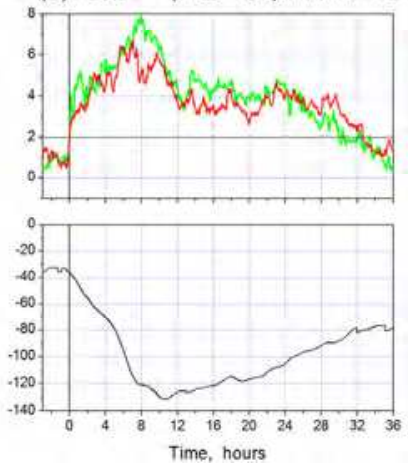

(c) $\mathrm{Dst}=-(80-100) \mathrm{nT}, \mathrm{N}=11$
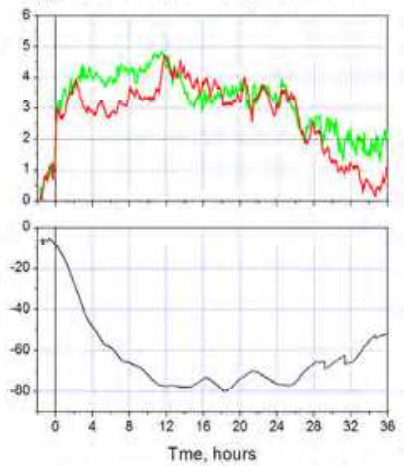

(f) $\mathrm{Dst}=-(160-240) \mathrm{nT}, \mathrm{N}=6$
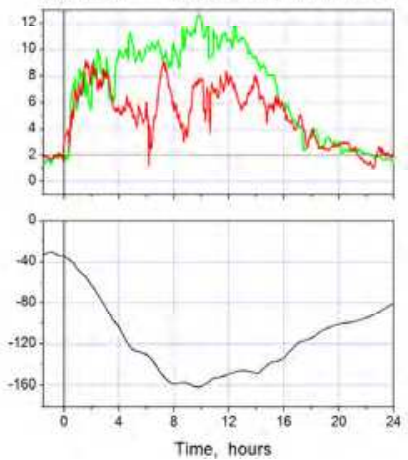

Fig. 8. Relationship between behavior of averaged $P C$ index (red) and $E_{K L}$ (green) quantities and development of magnetic storm Dst index (black) for 6 gradations of storm intensity: (a) $-30>$ Dst $>-50 \mathrm{nT}$, (b) $-50>$ Dst $>-80 \mathrm{nT}$, (c) $-80>$ Dst $>-100 \mathrm{nT}$, (d) $-100>$ Dst $>120 \mathrm{nT}$, (e) $130>D s t>160 \mathrm{nT}$, (f) $160>D s t>240 \mathrm{nT}$. The key date $(\mathrm{T}=0)$ is taken as a time of the persistent transition of the $E_{K L}$ value over the level of $2 \mathrm{mV} / \mathrm{m}$ (Troshichev et al., 2011c). 
persistently rises above the level of $2 \mathrm{mV} / \mathrm{m}$ was taken as a time (T=0) of the disturbance beginning, and the time when the $P C$ index persistently falls below the level of $2 \mathrm{mV} / \mathrm{m}$ was taken as a time of the recovery phase beginning.

Figure 8 shows the behavior of coupling function $E_{K L}$ and the $P C$ index, as well as corresponding changes in the Dst index for these 6 gradations. Results of case studies and statistical analysis (Figure 8) demonstrate the following regularities: geomagnetic field depression generally starts to develop as soon as $P C$ and $E_{K L}$ exceed the threshold of $\sim 2$ $\mathrm{mV} / \mathrm{m}$; as a rule, $P C$ and $E_{K L}$ simultaneously cross the threshold, although sometimes one goes ahead of other; when $P C\left(E_{K L}\right)$ demonstrates repetitive strong enhancements and decreases, the magnetic storm displays the appropriate multiple depressions with growth and dumping phases; persistent descent of $P C\left(E_{K L}\right)$ below the threshold level of $2 \mathrm{mV} / \mathrm{m}$ is indicative of the end of the storm main phase and transition to the recovery phase; " $P C$ saturation effect" is typical of events with $E_{K L}$ values $>6 \mathrm{mV} / \mathrm{m}$.

To derive statistical relationships between Dst and mean $P C\left(E_{K L}\right)$ values, the $1 \mathrm{~min}$ quantities $P C$ and $E_{K L}$ were averaged over the growth phase duration (the interval from time $\mathrm{T}=0$ to the time of the peak value of Dst (Dst(peak)). The averaged values PCgrowth and $E_{K L}$ growth were compared with value of maximal depression. It turned out (Figure 9) that under conditions of $E_{K L}<6 \mathrm{mV} / \mathrm{m}$, the relationship between Dst(peak) and PC (Dst = 24.8$\left.31.8^{*} P C\right)$ is of the same character as between $D s t\left(\right.$ peak) and $E_{K L}\left(D s t=24.9-30.9^{*} E_{K L}\right)$, although the correlation of Dst with $E_{K L}(\mathrm{R}=-0.74)$ is much lower than with $P C(\mathrm{R}=-0.87)$. Under
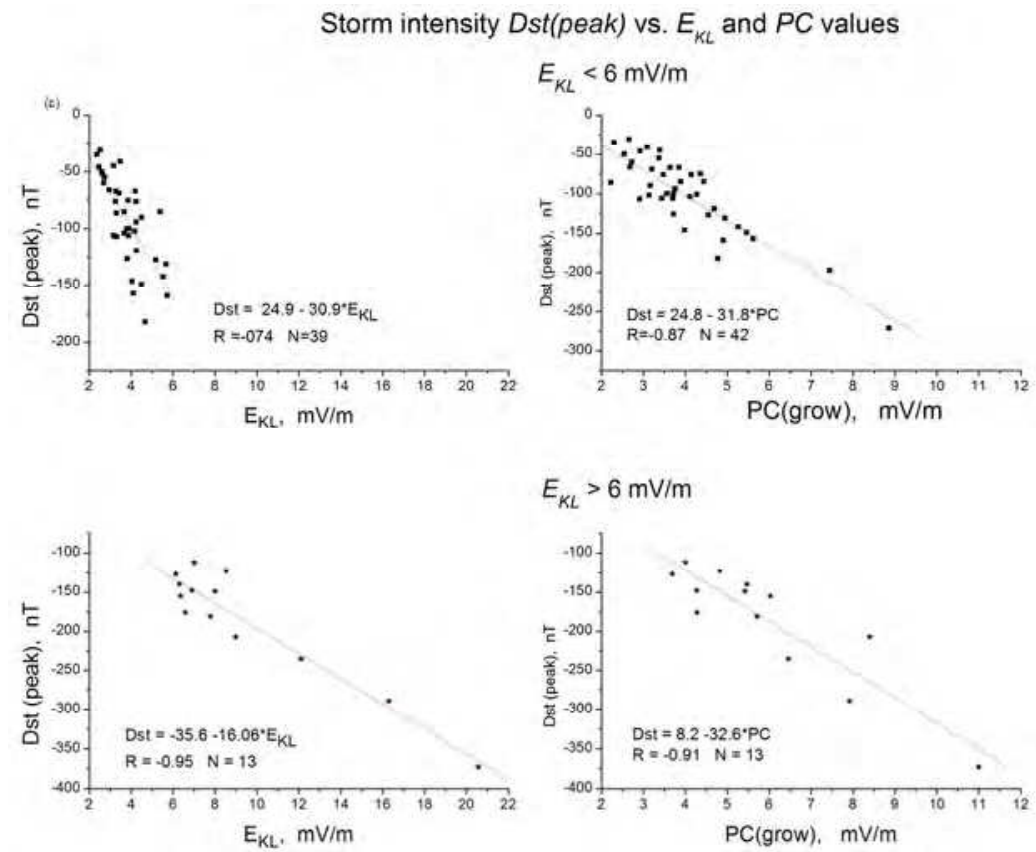

Fig. 9. Relationships between storm intensity Dst(peak) and quantities $E_{K L}$ growth and $P C$ growth averaged over the storm growth phase interval, derived for categories of $E_{K L}<6$ $\mathrm{mV} / \mathrm{m}$ and $E_{K L}>6 \mathrm{mV} / \mathrm{m}$ (Troshichev et al., 2011c) 
conditions $E_{K L}>6 \mathrm{mV} / \mathrm{m}$ the efficiency of $E_{K L}$ strongly decreases (Dst=-35.6-16.05* $\left.E_{K L}\right)$, whereas relationship between $D s t$ (peak) and $P C$ is practically unchanged (Dst=8.2-32.6PC). The evident slowing down of depression Dst(peak) for conditions of $E_{K L}>5-6 \mathrm{mV} / \mathrm{m}$ can be termined as a "Dst saturation effect" which is not seen in relations of Dst with the PC index.

Thus, all examined magnetic storms started as soon as the field $E_{K L}$ and the appropriate $P C$ index firmly exceeded the threshold of $\sim 2 \mathrm{mV} / \mathrm{m}$. The storm main phase lasted till the $E_{K L}$ and $P C$ steadily stands above this threshold level. The time of the firm descent of the $P C$ and $E_{K L}$ quantities below the same level of $\sim 2 \mathrm{mV} / \mathrm{m}$ is indicative of the storm transition to the recovery phase. The storm intensity Dst(peak) demonstrates the steady linear correlation with the $P C$ value averaged for the growth phase $P C$ (growth) for all storm intensities irrespective of $P C$ value. The storm dynamics correlate better with value and changes of the $P C$ index than with those of the $E_{K L}$ field that provides a weighty argument in support of the $P C$ index as a signature of the solar wind energy that entered into the magnetosphere.

\section{Conclusion}

The PC index has been introduced initially (Troshichev et al., 1988) as a characteristic of the polar cap magnetic activity related to the geoeffective interplanetary electric field $E_{K L}$ which was determined by formula of Kan \& Lee (1979). The recent studies (Troshichev et al., 2007; Janzhura et al., 2007, Troshichev \& Janzhura, 2009; Troshichev et al., 2011c) show that the PC index implication is more significant: the magnetospheric storms and substorms start only if the $P C$ index reaches the definite threshold value $(\sim 2 \mathrm{mV} / \mathrm{m}$ for storms, and $>1.5 \mathrm{mV} / \mathrm{m}$ for substorms); the substorm growth phase duration and substorm intensity are determined by the $P C$ growth rate and substorms are stopped as soon as $P C$ index falls below $1-1.5 \mathrm{mV} / \mathrm{m}$; the storm length is terminated by duration of period, when $P C>2 \mathrm{mV} / \mathrm{m}$, the storm intensity being linearly related to the $P C$ index averaged for the storm time interval; development of storms and substorms is better consistent with the $P C$ behavior than with the coupling function variations; and so on. In addition, it turned out that the PC index adequately responds to sharp changes in the solar wind dynamic pressure. All these experimentally established relationships make it possible to conclude that the $P C$ index should be regarded as an adequate and convenient proxy of the solar wind energy that entered into the magnetosphere.

If holding this point of view it becomes obvious why the storm and substorm indicators should correlate better with the $P C$ index than with coupling function $E_{K L}$ (since the coupling function $E_{K L}$ characterizes the state of solar wind coupling with the magnetosphere, whereas the $P C$ index characterizes the energy that entered into the magnetosphere); why the $P C$ index increase precedes storm and substorms (because growth of the entered energy above the level of energy dissipation is followed by realizing the energy excess in form of magnetic disturbances); why the sawtooth substorms demonstrate the distinct periodicity under conditions of steadily high energy supply (because the persistently high entered energy ensures the extreme intensity of field aligned currents discharging the current generator which power is limited by finite plasma pressure gradients in the closed magnetosphere (see Troshichev et al., 2012)).

As far as the $P C$ index characterizes the energy that entered into the magnetosphere in course of solar wind - magnetosphere coupling, the index can be used to monitor the 
solar wind geoefficiency and state of magnetosphere. Since disturbances in magnetosphere are always preceded by energy input, the $P C$ index usage makes it possible to realize the space weather nowcasting (including the auroral ionosphere state and even the anomalous processes in polar atmosphere). At present, the PCN and PCS indices are published at sites:

PCN ftp://ftp.space.dtu.dk/WDC/indices/pen/

PCS http://www.geophys.aari.ru/

\section{References}

Akasofu, S.-I. (1981). Energy coupling between the solar wind and the magnetosphere, Space Sci. Rev., vol.28, 121

Antonova, E.; Kirpichev I. \& Stepanova, M. (2006). Field-aligned current mapping and the problem of the generation of magnetospheric convection. Adv. Space Res., vol.38, 1637 - 1641, doi:10.1016/j.asr.2005.09.042

Antonova, E,; Kirpichev, I.; Ovchinnikov, I.; Pulinets, M.; Znatkova, S.; Orlova, K. \& Stepanova, M. (2011). Topology of High-Latitude Magnetospheric Currents. In: Fujimoto M, Liu W (eds) The Dynamic Magnetosphere. IAGA Special Sopron Book Series, V 3, Springer Dordrecht Heidelberg London New York, pp.201-210

Arnoldy, R. (1971). Signature in the interplanetary medium for substorms. J. Geophys. Res., vol.76, 5189-5201

Baliff, J.; Jones, D.; Coleman, P.; Davis, L. \& Smith, E. (1967). Transverse fluctuations in the interplanetary magnetic field: a requisite for geomagnetic variability. J. Geophys. Res., vol.72, 4357-4362

Birkeland, K. (1908). The Norwegian Aurora Polaris Expedition 1902-1903, vol.1 Christiania

Burton, R.; McPherron, R. \& Russell, C. (1975). An empirical relationship between interplanetary conditions and Dst. J. Geophys. Res., vol.80, 4204-4214

Bythrow, P. \& Potemra, T. (1983). The relationship of total Birkeland currents to the merging electric field. Geophys Res. Lett., vol.10, 573-576

Chapman, S. (1963). Solar plasma, geomagnetism and aurora, in Geophysics: The Earth's Environment. C.DeWitt, (Ed), Gordon and Breach Sci.Pub., New York - London

Clauer, C.; Cai, X.; Welling, D.; DeJong, A. \& Henderson, M. (2006). Characterizing the 18 April 2002 storm-time sawtooth events using ground magnetic data. J. Geophys. Res., vol.111, A04S90, doi:10.1029/2005JA011099

Fairfield, D. \& Cahill, L. (1966). Transition region magnetic field and polar magnetic disturbances. J. Geophys. Res., vol.71, 6829-6846

Foster, J.; Fairfield, D.; Ogilvie, K. \& Rosenberg, T. (1971). Relationship of interplanetary parameters and occurrence of magnetospheric substorms. J. Geophys. Res., vol.76, 6971-6975

Garrett, H.; Dessler, A. \& Hill, T. (1974). Influence of solar wind variability on geomagnetic activity. J. Geophys. Res., vol.79, 4603-4610

Gizler, V.; Semenov, V. \& Troshichev, O. (1979). The electric fields and currents in the ionosphere generated by field-aligned currents observed by TRIAD. Planet. Space Sci., vol.27, 223-231 
Henderson, M.; Reeves, G.; Skoug, R.; Thomsen, M.; Denton, M.; Mende, S.; Immel, T.; Brandt, P. \& Singer, H. (2006a) Magnetospheric and auroral activity during the 18 April 2002 sawtooth event. J. Geophys. Res., vol.111, A01S90, doi:10.1029/2005JA011111

Henderson, M.; Skoug, R.; Donovan, E; et al. (2006b). Substorm during the 10 August 2000 sawtooth event. J. Geophys. Res., vol.111, A06206, doi:10.1029/2005JA011366

Hirshberg, J. \& Colburn D. (1969). Interplanetary field and geomagnetic variations - a unified view. Planet. Space Sci., vol.17, 1183-1206

Iijima, T. \& Potemra, T. (1976). The amplitude distribution of field-aligned currents at northern high latitudes observed by Triad. J. Geophys. Res., vol.81, 2165-2174

Iijima, T. \& Potemra, T. (1978). Large-scale characteristics of field-aligned currents associated with substorms. J. Geophys. Res., vol.83, 599-615

Iijima, T. \& Potemra, T. (1982). The relationship between interplanetary quantities and Birkeland current densities. Geophys. Res. Lett., vol.4, 442-445

Iijima, T.; Potemra, T. \& Zanetti, L. (1997). Contribution of pressure gradients to the generation of dawnside region 1 and region 2 currents. J. Geophys. Res., vol.102: 27069-27081

Janzhura, A. \& Troshichev, O. (2008). Determination of the running quiet daily geomagnetic variation, J. Atmos. Solar-Terr. Phys., vol.70, 962-972

Janzhura, A.; Troshichev, O. \& Stauning, P. (2007). Unified PC indices: Relation to the isolated magnetic substorms, J. Geophys. Res., vol.112, A09207, doi: 10.1029/2006JA012132

Kamide, Y. (1974). Association of DP and DR fields with the interplanetary magnetic field variations. J. Geophys. Res., vol.79, 49

Kan, J. \& Lee, L. (1979). Energy coupling function and solar wind-magnetosphere dynamo. Geophys. Res. Lett., vol.6, 577-580

Kane, R. (1974). Relationship between interplanetary plasma parameters and geomagnetic Dst. J. Geophys. Res., vol. 79, 64-72

Kokubun, S. (1972). Relationship of interplanetary magnetic field structure with development of substorm and storm main phase. Planet. Space Sci., vol.20, 10331050

Kuznetsov, B. \& Troshichev O. (1977). On the nature of polar cap magnetic activity during undisturbed periods. Planet. Space Sci., vol.25, 15-21

Langel, R. (1975). Relation of variations in total magnetic field at high latitude with parameters of the IMF and with DP2 fluctuations. J. Geophys. Res., vol.80, 1261-1270

Lui, A.; Hori, T.; Ohtani, S.; Zhang, Y.; Zhou, X. Henderson, M.; Mukai, T.; Hayakawa, H. \& Mende, S. (2004). Magnetotail behavior during storm time 'sawtooth injections'. J. Geophys. Res., vol.109, A10215, doi:10.1029/2004JA010543

Maezawa, K. (1976). Magnetospheric convection induced by the positive and negative Z components of the interplanetary magnetic field: quantitative analysis using polar cap magnetic records. J. Geophys. Res., vol.81, 2289-2303

Mansurov, S. (1969). A new evidence for relationship between the space and earth magnetic fields. Geomagn. Aeronomy, vol.9, 768-770 (in Russian) 
McDiarmid, I.; Budzinski, E.; Wilson, M. \& Burrows J. (1977). Reverse polarity field-aligned currents at high latitudes. J. Geophys. Res., vol.82, 1513-1518

Meng, C-I.; Tsurutani, B.; Kawasaki, K. \& Akasofu, S-I. (1973). Cross-correlation analysis of the AE-index and the interplanetary magnetic field Bz component. J. Geophys. Res., vol.78, 617-629

Murayama, T. \& Hakamada, K. (1975). Effects of solar wind parameters on the development of magnetospheric substorms. Planet. Space Sci., vol.23, 75-91

Newell, P.; Sotirelis, T.; Liou, K.; Meng, C-I. \& Rich, F. (2007) A nearly universal solar wind magnetosphere coupling function inferred from 10 magnetospheric state variables. J. Geophys. Res., vol.112, A01206, doi:10.1029/2006JA012015

Newell, P.; Sotirelis, T.; Liou, K. \& Rich, F. (2008). Pairs of solar wind-magnetosphere coupling functions: combining a merging term with a viscous term works best. $J$. Geophys. Res., vol.113, A04218, doi:10.1029/2007JA012825

Nisbet, J.; Miller, M. \& Carpenter, L. (1978). Currents and electric fields in the ionosphere due to field-aligned auroral currents. J. Geophys. Res., vol.83, 2647

Nishida, A. (1968). Geomagnetic DP2 fluctuations and associated magnetospheric phenomena. J. Geophys. Res., vol.73, 1795-1803

Perreault, P. \& Akasofu, S-I. (1978). A study of geomagnetic storms. Geophys. J. R. Astr. Soc., vol.54, 57

Pudovkin, M.; Raspopov, O.; Dmitrieva, L.; Troitskaya, V. \& Shepetnov, R. (1970). The interrelation between parameters of the solar wind and the state of the geomagnetic field. Ann. Geophys., vol.26,: 389-392

Reiff, P. \& Luhmann, J. (1986). Solar wind control of the polar-cap voltage. In: Solar Wind Magnetosphere Coupling, Kamide, Y. \& Slavin, J. (eds), pp 453-476, Terra Sci, Tokyo

Rossolenko, S.; Antonova, E.; Yermolaev, Y.; Verigin, M.; Kirpichev, I. \& Borodkova, N. (2008). Turbulent Fluctuations of Plasma and Magnetic Field Parameters in the Magnetosheath and the Low-Latitude Boundary Layer Formation: Multisatellite Observations on March 2, 1996. Cosmic. Res., vol. 46, 373-382 (in Russian).

Rostoker, G. \& Falthammar, C. (1967). Relationship between changes in the interplanetary magnetic field and variations in the magnetic field at the Earth's surface. J. Geophys. Res., vol.72, 5853-5863

Russel, C.; McPherron, R. \& Burton, R. (1974). On the cause of geomagnetic storms. J. Geophys. Res., vol.79, 1105

Sergeev, V. \& Kuznetsov, B. (1981) Quantitative dependence of the polar cap electric field on the IMF BZ component and solar wind velocity. Planet. Space Sci., vol.29, 205-213

Spencer, E.; Rao, A.; Horton, W. \& Mays, M. (2009). Evaluation of solar - magnetosphere coupling functions during geomagnetic storms with the WINDMI model. J. Geophys. Res., vol.114, A02206, doi: 10.1029/2008JA013530

Stepanova, M.; Antonova, E., Bosqued, J. \& Kovrazhkin, R. (2004). Azimuthal plasma pressure reconstructed by using the Aureol-3 satellite date during quiet geomagnetic conditions. Adv. Space Res., Vol. 33, 737-741

Stepanova, M.; Antonova, E. \& Bosqued J. (2006). Study of plasma pressure distribution in the inner magnetosphere using low-altitude satellites and its importance for the large-scale magnetospheric dynamics, Adv. Space Res., Vol. 38, 1631-1636 
Sugiura, M. (1976). Hourly values of equtorial Dst for the IGY, Ann. Int.Geophys. Year, 35, 1.

Svalgaard, L. (1968). Sector structure of the interplanetary magnetic field and daily variation of the geomagnetic field at high latitudes. Det Danske meteorologiske institute Charlottenlund, preprint R-6

Troshichev, O. (1975). Magnetic disturbances in polar caps and parameters of solar wind. In: Substorms and magnetospheric disturbances. Nauka, Leningrad, pp 66-83, (in Russian)

Troshichev, O. (1982). Polar magnetic disturbances and field-aligned currents. Space Sci. Rev., vol. 32, 275-360

Troshichev, O. \& Tsyganenko, N. (1978). Correlation relationships between variations of IMF and magnetic disturbances in the polar cap. Geomagn. Res., vol.25, 47-59 (in Russian)

Troshichev, O. \& Andrezen, V. (1985). The relationship between interplanetary quantities and magnetic activity in the southern polar cap. Planet. Space Sci., vol.33, 415

Troshichev, O. \& Janzhura, A. (2009). Relationship between the PC and AL indices during repetitive bay-like magnetic disturbances in the auroral zone. J. Atmos. Solar-Terr. Phys., 71, 1340-1352

Troshichev, O.; Gizler, V.; Ivanova, I. \& Merkurieva, A. (1979). Role of field-aligned currents in generation of high latitude magnetic disturbances. Planet. Space Sci., vol.27, 14511459

Troshichev, O.; Andrezen, V.; Vennerstrøm, S. \& Friis-Christensen, E. (1988). Magnetic activity in the polar cap - A new index. Planet. Space Sci., vol.36, 1095,.

Troshichev, O.; Janzhura, A. \& Stauning, P. (2006). Unified PCN and PCS indices: Method of calculation, physical sense and dependence on the IMF azimuthal and northward components. J. Geophys. Res., vol.111, A05208, doi:10.1029/2005JA011402

Troshichev, O.; Janzhura, A. \& Stauning, P. (2007). Magnetic activity in the polar caps: Relation to sudden changes in the solar wind dynamc pressure, J. Geophys. Res., vol.112, A11202, doi:10.1029/2007JA012369,

Troshichev, O.; Podorozhkina, N. \& Janzhura, A. (2011a). Invariability of relationship between the polar cap magnetic activity and geoeffective interplanetary electric field. Ann. Geophys., vol.29, 1-11, doi:10.5194/angeo-29-1-2011

Troshichev, O.; Stauning, P.; Liou, K. \& Reeves, G. (2011b). Saw-tooth substorms: inconsistency of repetitive bay-like magnetic disturbances with behavior of aurora. Adv. Space Res., vol.47, 702-709, doi: 10.1016/j.asr.2010.09.026

Troshichev, O.; Sormakov, D. \& Janzhura, A. (2011c). Relation of PC index to the geomagnetic storm Dst variation. J. Atmos. Solar-Terr. Phys., vol.73 611-622, doi:10.1016/j.jastp.2010.12.015

Troshichev, O.; Sormakov, D. \& Janzhura, A. (2012). Sawtooth substorms generated under conditions of the steadily high solar wind energy input into the magnetosphere: Relationship between $P C, A L$ and ASYM indices. Adv. Space Res., doi:10.1016/j.asr.2011.12.011

Wilcox, J.; Schatten, K. \& Ness, N. (1967). Influence of interplanetary magnetic field and plasma on geomagnetic activity during quiet-sun conditions. J. Geophys. Res., vol.72, 19-26 
Wing, S. \& Newell, P. (2000). Quiet time plasma sheet ion pressure contribution to Birkeland currents. J. Geophys. Res., vol.105, 7793-7802

Xing, X.; Lyons, R,; Angelopoulos, V.; Larson, D; McFadden, J.; Carlson, C.; Runov, A. \& Auster, U. (2009). Azimuthal plasma pressure gradient in quiet time plasma sheet. Geophys. Res. Lett., vol.36, L14105, doi:10.1029/2009GL038881

Zmuda, A. \& Armstrong, J. (1974). The diurnal flow pattern of field-aligned currents. J. Geophys. Res., vol.79, 4611-4519 


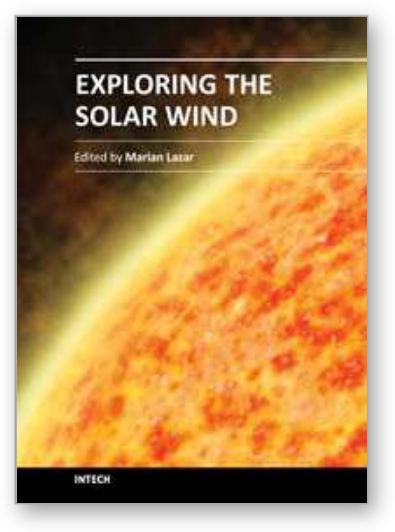

\author{
Exploring the Solar Wind \\ Edited by Dr. Marian Lazar
}

ISBN 978-953-51-0339-4

Hard cover, 462 pages

Publisher InTech

Published online 21, March, 2012

Published in print edition March, 2012

This book consists of a selection of original papers of the leading scientists in the fields of Space and Planetary Physics, Solar and Space Plasma Physics with important contributions to the theory, modeling and experimental techniques of the solar wind exploration. Its purpose is to provide the means for interested readers to become familiar with the current knowledge of the solar wind formation and elemental composition, the interplanetary dynamical evolution and acceleration of the charged plasma particles, and the guiding magnetic field that connects to the magnetospheric field lines and adjusts the effects of the solar wind on Earth. I am convinced that most of the research scientists actively working in these fields will find in this book many new and interesting ideas.

\title{
How to reference
}

In order to correctly reference this scholarly work, feel free to copy and paste the following:

Oleg Troshichev (2012). Ground-Based Monitoring of the Solar Wind Geoefficiency, Exploring the Solar Wind, Dr. Marian Lazar (Ed.), ISBN: 978-953-51-0339-4, InTech, Available from:

http://www.intechopen.com/books/exploring-the-solar-wind/ground-based-monitoring-of-the-solar-windgeoefficiency

\section{INTECH}

open science | open minds

\section{InTech Europe}

University Campus STeP Ri Slavka Krautzeka 83/A 51000 Rijeka, Croatia Phone: +385 (51) 770447 Fax: +385 (51) 686166 www.intechopen.com

\author{
InTech China \\ Unit 405, Office Block, Hotel Equatorial Shanghai \\ No.65, Yan An Road (West), Shanghai, 200040, China \\ 中国上海市延安西路65号上海国际贵都大饭店办公楼405单元 \\ Phone: +86-21-62489820 \\ Fax: +86-21-62489821
}


(C) 2012 The Author(s). Licensee IntechOpen. This is an open access article distributed under the terms of the Creative Commons Attribution 3.0 License, which permits unrestricted use, distribution, and reproduction in any medium, provided the original work is properly cited. 